\title{
Optimalization of Social Media as a Counter to Islamophobia in Australia
}

\section{Optimalisasi Media Sosial Sebagai Counter Islamophobia di Australia}

\author{
Shinta Lailatul Maghfiroh ${ }^{1 *}$, Siti Rohma \\ 1,2Pascasarjana,Universitas Islam Negeri Sunan Ampel, Surabaya
}

OPEN ACCESS

ISSN 2541-2841 (online) ISSN 2302-6790 (print)

Edited by:

Sitti Murni Kaddi

*Correspondence:

Shinta Lailatul

Maghfiroh

shintamaghfiroh2@gmai

l.com

Citation:

Maghfiroh L. S and Rohma S (2021) Optimalisasi Media Sosial Sebagai Counter Islamophobia di Auatralia, Kanal, 9(2).

Doi:10.21070/kanal.v9i2.1196

\begin{abstract}
Australia is a multicultural country, but Islamophobia is still developing, so it needs a way to stop that view. This study aims to prove that Islamophobia in the West can be minimized. This paper is a literature study with a political communication approach regarding the optimization of social media as a barrier to Islamophobia in Australia. Data collection comes from literature such as articles, journals, reports, policy briefs, news books, and other sources concerning social media and Islamophobia in Australia. Data analysis techniques were carried out with three stages namely data reduction, data presentation and verification. The object of study in this study is the optimization of social media to counter Islamophobia in Australia by Onepath Networks. The study results state that social media is quite optimal in order to minimize the development of Islamophobia issues. Onepath Network as one of the Islamic organizations in Australia, uses social media to preach. Da'wah is done with videos and documentaries that are shown on Youtube and even cinemas on Islamic dialogue. Since the Onepath Network was formed, Islamophobia in Australia began to diminish and is proven by Muslims who began to participate in various fields, including government, many mosques began to be built and many Islamic schools were established.

Keywords: Islamophobia, Social Media, Policy, Australia.
\end{abstract}

\begin{abstract}
Abstrak
Australia merupakan negara multikultural, namun Islamophobia masih berkembang, sehingga membutuhkan cara untuk menghentikan pandangan tersebut. Penelitian ini bertujuan untuk membuktikan bahwa Islamophobia di Barat dapat diminimalisir. Tulisan ini merupakan studi literatur dengan pendekatan komunikasi politik mengenai optimalsisasi media sosial sebagai penghalang Islamophobia di Australia. Pengumpulan data berasal dari literatur-literatur seperti artikel, jurnal, laporan, policy brief, buku berita, dan sumber lain menegenai media sosial dan Islamophobia di Australia. Teknik analisa data yang dilakukan dengan tiga tahap yakni reduksi data, penyajian data dan verifikasi. Objek kajian dalam penelitian ini adalah optimalisasi media sosial guna mengcounter Islamophobia di Australia oleh Onepath Networks.
\end{abstract}


Hasil studi menyatakan bahwa media sosial cukup optimal guna meminimalisir perkembangan isu Islamophobia. Onepath Network sebagai salah satu organisasi Islam di Australia, memanfaatkan media sosial untuk berdakwah. Dakwah ini dilakukan dengan video dan film dokumenter yang ditayangkan melalui Youtube bahkan bioskop mengenai dialog keislaman. Semenjak jaringan Onepath Network terbentuk Islamophobia di Australia mulai berkurang dan dibuktikan dengan umat Muslim yang mulai ikut serta dalam berbagai bidang, termasuk pemerintahan, banyak Masjid mulai dibangun serta sekolah Islam yang banyak berdiri.

Kata Kunci: Islamophobia, Media Sosial, Kebijakan, Australia.

\section{PENDAHULUAN}

Australia merupakan negara persemakmuran yang dipimpin oleh Ratu Inggris. Australia mengakui kedaulatan Ratu Inggris dan diwakili oleh Gubernur Genderal di Australia sebagai orang kepercayaan Ratu Inggris untuk memimpin Australia. Sistem politik negara ini adalah parlemen demokrasi yang beroperasi sesuai model Westminster. Model Westminster berarti Majelis Parlemen menunjuk Perdana Menteri. Pemerintah Australia menganut sistem federalisme, dimana kekuasaan dibagi antara pemerintah nasional (persemakmuran) dan konstitusi. Hal ini berarti, secara garis besar kepala negara Australia adalah Gubernur Jenderal yang ditunjuk oleh Perdana Menteri melalui persetujuan Ratu Inggris. Australia menganut parlemen bikameral yang terdiri dari 76 anggota Senat dan 150 anggota Dewan Perwakilan, dengan setiap negara bagian memiliki 12 Senator dan dua Senator di setiap wilayah (Library of Congress, 2005).

Australia merupakan negara plural karena dihuni oleh beberapa kelompok etnis dan agama. kelompok etnis yang menghuni negara ini adalah $92 \%$ etnis Kaukasia, $6 \%$ etnis Asia dan $2 \%$ etnis Aborigin. Agama di Australia, terdiri dari masyarakat Kristen, Budha, Islam, Hindu, dan Yahudi. Menurut survei dari University of South Australia, pada tahun 2016, mayoritas penduduk Australia beragama Kristen dengan 52,1\% dari jumlah penduduk. Agama kedua yang terbanyak adalah Islam dengan 2,6\%, selanjutnya Budha dengan 2,4\%, Hindu 1,9\%, Yahudi 0,4\% dan sisanya menyatakan tidak beragama (University of South Australia, 2018). Umat Muslim yang berjumlah 2,6\% dari populasi penduduk di Australia menunjukkan bahwa Muslim di Australia adalah minoritas. Hal ini dikarenakan jumlah Umat Kristen mencapai lebih dari separuh populasi di Australia.

Di Australia meskipun kaum Muslim adalah minoritas, namun mereka mendapatkan kebebasan untuk melakukan ibadah, tetapi mereka akan mengalami kesulitan ketika akan membangun Masjid (Kartini, 2016). Hubungan sosial masyarakat Australia mengalami pasang surut antara umat Muslim dan Non-Muslim. Hal ini dikarenakan oleh beberapa faktor seperti sejarah, generalisasi berlebihan eksistensi komunitas Muslim di Australia dan situasi baik nasional maupun internasional. Pada sisi sejarah, Islam datang pada tahun 1750 sehingga terjalin hubungan dagang dan perkawinan (Jatmika, 2015).
Selanjutnya pemerintah Australia mengundang pengendara Unta dari Afghanistan. Kemudian imigran dari negara Eropa dan Timur Tengah. Pada sisi generalisasi berlebihan eksistensi komunitas Muslim mengalami perkembangan pesat. Hal ini dianggap sebagai ancaman bagi kaum Non-Muslim, sehingga muncul kebijakan White Australia Policy tahun 1901 (Kartini, 2016). Kebijakan ini berpengaruh terhadap imigran yang semakin surut. Tahun 1958 kebijakan tersebut dihapus dan berdampak terhadap banyaknya imigran dari Arab dan Timur Tengah tahun 1972. Pada situasi nasional maupun internasional, isu yang sering mempengaruhi hubungan Muslim dan Non-Muslim adalah isu mengenai terorisme. Misalnya, ketika World Trade Center di bom pada 11 September 2001. Peristiwa ini menyebabkan umat Islam mendapatkan sorotan karena dianggap sebagai agama teroris dan kembali memunculkan Islamophobia di seluruh negara barat (Lean, 2012).

Islamophobia merupakan sikap negatif dan musuh terhadap Islam dan umat Muslim. Istilah Islamophobia memiliki sejarah yang panjang. Pada tahun 2014, Islamophobia mulai benar-benar berkembang di Australia (Mills, 2014). Peristiwa ini ditandai dengan pembunuhan Haider di Melbourne pada 23 September (Houston et. al., 2014). Sejak saat itu, undang-undang anti-terorisme mulai diperkenalkan oleh Parlemen (Berg, 2014). Islamophia di negara ini diperparah dengan ucapan Hanson yang menyatakan bahwa umat Muslim boleh tinggal di Australia selama mereka beraga Kristen (Packham, 2007). Pernyataan itu menyebabkan umat Muslim di Australia mengalami diskriminasi (AHRC, 2011).

Islamophobia semakin berkembang dan mendarah daging, salah satunya dikarenakan bantuan dari media. Media massa memberikan peran penting dalam membentuk opini publik, terutama mengenai eksistensi kelompok Muslim. Namun, media massa terkadang bias dalam pemberitaannya, sehingga sikap masyrakat yang biasa saja atas suatu hal dapat diekspos berbeda oleh media. Hal ini sering kali menimbulkan kesalahpahaman khalayak mengenai pemberitaan terhadap umat Islam terutama yang berkaitan dengan isu terorisme sehingg berdampak pada perkembangan Islamophobia di Australia. 
Islamophobia yang semakin berkembang, tidak dibiarkan begitu saja oleh umat Muslim di Australia. Secara garis besar, terdapat dua hal yang dilakukan oleh komunitas Muslim untuk meng-counter Islamophobia di Australia. Pertama, melalui komunitas Muslim di Australia. Negara kurang lebih memiliki empat organisasi muslim yang terkenal di kalangan penduduk Australia, yakni Australian Federation of Islamic Council (AFIC), Federation of Islamic Societies (FIS), Moslem Student Association (MSA), dan Moslem Women's Center (MWC) (Kurniawan, 2014). Kedua, melalui media sosial untuk melakukan dakwah. Salah satu akun media sosial yang gemar melakukan dakwah adalah Onepath Networks.

Onepath Networks merupakan media salah satu organisasi yang didirkan oleh Malaz Manjani pada tahun 2014 di Sydney, Australia (Om, 2015). Organisasi ini melakukan dakwah melalui konten berupa video dakwah bertema Islam, Last Chance yakni film berdurasi 45 menit mengenai pemuda Muslim yang tergoda untuk menjual narkoba dan tayang di bioskop Australia (Melelawar, 2017). Organisasi ini mendapatkan satu juta dollar dari berbagai iklan yang mensponsori channel yang mereka bangun. Organisasi banyak mendapatkan dukungan dari berbagai pihak, hingga pernah diberitakan di Sydney Morning Herald (Irfan, 2015).

Topik ini sangat menarik untuk diteliti, karena Islamophobia masih tetap eksis hingga saat ini. Hal tersebut dibuktikan dengan perlunya alat untuk melakukan counter terhadap perkembangan mindset penduduk Australia mengenai Islamophobia, agar diskriminasi terhadap kaum Muslim tidak lagi terjadi. Penelitian ini fokus terhadap upaya yang dilakukan oleh umat Islam di Australia untuk meminimalisir Islamophobia.

\section{METODE PENELITIAN}

Penelitian ini menggunakan studi literatur dengan perspektif komunikasi yang dilakukan pada bulan Januari sampai Juli 2020. Pengumpulan data berasal dari literatur-literatur seperti artikel, jurnal, laporan, policy brief, buku berita, dan sumber lain menegenai media sosial dan Islamophobia di Australia. Teknik analisa data yang dilakukan dengan tiga tahap yakni reduksi data, penyajian data dan verifikasi. Objek kajian dalam penelitian ini adalah optimalisasi media sosial guna counter Islamophobia di Australia oleh Onepath Networks.

\section{HASIL DAN PEMBAHASAN}

\section{Islam di Australia}

Agama Islam di Australia merupakan afiliasi agama minoritas. Menurut survey University of South Australia, jumlah umat Islam sejumlah 604.200 orang atau sekitar 2,6\% dari seluruh penduduk Asutralia (University of South Australia, 2018). Umat Muslim di Australia didominasi oleh
Sunni dan Syiah, dengan madzhab yang berbeda. Berbagai aliran yang ada di Australia diantaranya adalah Ahmadiyah, Ibadi keturunan Oman, serta orang-orang sufi (Melton \& Baumann, 2010). Oleh sebab itu, komunitas Muslim di Australia bukan hanya satu, tetapi lebih dari satu. Komunitas Muslim Australia juga terbagi atas ras, etnis, budaya maupun bahasa (Burke, 2012).

Sebagai negara federal yang dikuasai oleh dua kekuatan politik, menyebabkan dua kekuatan tersebut harus menerapkan kebijakan yang adil terhadap kaum Muslim di Australia. Kebijakan yang diterapkan lebih kepada penerapan nilai-nilai liberalisme untuk menjaga keserasian antar umat beragama. Sikap dua kekuatan politik ini lebih mengutaman konsistensi dalam prinsip sekulerisme dalam menjalankan pemerintahan. Hal ini berdampak terhadap komunitas Muslim Australia sebagai objek untuk sosialisasi nilai liberal dan peradaban barat. Prinsip sekulerisme ini menyebabkan pemerintah memegang teguh peradaban Barat yang memisahkan kegiatan sosial-politik dari keagamaan. Pemerintah memandang komunitas Muslim sebagai komunitas yang tidak mengunggulkan identitas keagamaan dalam kehidupan sosial, sehingga muncul program multikulturalisme. Program multikulturalisme layaknya koleksi budaya bukan cita-cita kelompok sosial beragama, artinya komunitas Islam dianggap sebagai bagian dari koleksi budaya.

Pemerintah Australia menjaga sistem politik warisan Inggris, yakni Parlemen memiliki otoritas tertinggi dalam penyelenggaraan pemerintahan. Sementara, pemerintah adalah bagian dari parlemen, sehingga semua Undang-Undang harus bersumber dari aspirasi masyarakat tanpa rujukan dari keagamaan. Kedaulatan Tuhan tidak diterima dalam praktik politik di Australia. Pemerintah melakukan liberalisasi komunitas Muslim untuk menanamkan nilai-niai liberal dan peradaban Barat. Percaturan kekuatan politik melandasi kebijakan pemerintah federal untuk melakukan pengawasan ketat terhadap kelompok-kelompok Islam terutama yang dituduh teroris. Undang-Undang anti terorisme semakin membebai komunitas Muslim karena selalu menjadi sasaran intelejen dan kepolisian. Namun, percaturan kekuatan politik melandasi hak komunitas Muslim dan mendapatkan jaminan hidup sesuai prinsip Welfare State (Kartini, 2016).

Selain terkait dengan kebijakan di Australia, kehidupan Muslim di Australia juga terkait dengan peristiwa internasional. Peristwa internasional yang memiliki kaitan dengan Islam akan berimbas pada kehidupan Muslim di Australia. Misalnya, setelah Perang Teluk 1991, Irak menginvasi Kuwait yang berakibat pada Irak yang diserang oleh sekutu, serta peristiwa teorisme yang pada 11 September 2001 di New York. Hal tersebut berimbas pada kekerasan yang terjadi terhadap orang Muslim di Australia. Pasca peristiwa 9/11, agenda perang melawan teorisme gencar di promosikan oleh Amerika Serikat. Australia sebagai sekutu terdekat AS, melakukan hal yang sama hingga muncul Undang-Undang anti teorisme. Undang-Undang tersebut menjadi alasan beberapa penduduk Muslim Australia ditangkap. Keadaan ini membuat umat Muslim di Australia khawatir, karena tanpa bukti yang kuat umat Muslim bisa saja ditangkap dengan alasan melawan 
terorisme (Kartini, 2016). Gerakan melawan terorisme yang dipromosikan di Australia nyatanya adalah teror yang nyata bagi umat Muslim.

Kebijakan anti-teoror yang diterapkan justru membuat radikalisme tumbuh di Australia. Menurut Royal Institute of International Affairs menyatakan bahwa invasi yang dilakukan oleh Amerika Serikat terhadap Irak menimbulkan kebencian di hati umat Muslim. Peristiwa itu berimbas pada perekrutan militan Muslim untuk bergabung dengan Al-Qeda, mengumpulkan dana sekaligus menggencarkan propaganda (Royal International Affairs, 2014). Pada tahun 2002, pemuda Muslim Australia melakukan aksi bom bunuh diri di Australia sebagai bentuk protes atas kebijakan Australia yang sangat agresif terhadap umat Islam. Hal ini disetujui oleh Aziza Abdel Halim sebagai Presiden Muslim Women's National Network Australia,yang menyatakan bahwa banyak pemuda Islam yang berpikiran radikal karena dampak dari kebijakan Australia. Oleh sebab itu, diperlukan kajian ulang mengenai kebijakan Australia terhadap dunia Islam yang masih kontraproduktif (Kartini, 2016).

\section{Islamophobia di Australia}

Pada masa Perang Salib, Islam telah dianggap sebagai kekerasan dan dianggap sebagai praktek menyimpang (Bouma, 2011). Konfrontasi antara Islam dan Barat, seperti kolonialisme banyak didengungkan untuk memperkuat persepsi negatif mengenai umat Islam (Cesari, 2011). Kolonial menggunakan wacanaa anti-Islam untuk tetap membuat umat muslim menjadi tidak rasional dan terbelakang (Zebiri, 2011). Istilah Islamophobia sendiri sebenarnya muncul pada tahun 1922 di Prancis, yakni "Islamophobie" (Cesari, 2020). Seorang penulis bernama Etienne Nasreddine Dinet mencoba mendalami mengani Islamophobia dan mendapatkan bahwa istilah tersebut digunakan adalah lambang bagi orang yang membuat generalisasi yang salah tentang Muslim, salah mengartikan Islam atau menampilkan kebencian dan permusuhan yang tidak berdasar. Dinet merasa bahwa istilah ini muncul sebagai motivasi politik yang didorong oleh kepentingan pribadi (Karaoglu, 2018). Fakta ini didukung oleh Edward yang menyatakan bahwa negara Barat telah lama mengaitkan Islam dengan citra negatif, stereotip bahkan sentimen (Said, 1979).

Meskipun Muslim di Australia telah mengalami diskriminasi sejak akhir abad-19, perilaku anti muslim sebenarnya sudah terjadi sejak awal 1980-an (Dunn, 2001; Isakhan, 2010; Kabir, 2006). Pertumbuhan populasi Muslim di Australia yang sangat membeludak pada tahun tersebut, perhatian dan ketertarikanterhadap Islam oleh politisi dan publik, serta respon peristiwa internasional seperti revolusi Iran 1979 dan Intifada pertama Palestina tahun 1987 adalah penyebab diskriminasi terjadi (Espasito, 2011; Said, 1997). Sejak awal 1990-an istilah Islamophobia muncul secara politis di Australia (Human Rights and Equal Opportunity Commission, 1991). Peristiwa World Trade Center 2001 justru dimanfaatkan untuk membaut ketakutan baru, yakni terorisme untuk menekan kemanan nasional dan menjadi isu yang diangkat untuk pemilu taun 2001 saat itu (Fidler, 2011).
Periode 2001, isu yang kembali terangkat antara pencari suaka dan terorisme yang dianggap sebagai ancaman di Australia. Peter Maning (2004) menyatakan bahwa terdapat hubungan antara pencari suaka, terorisme, dan Muslim. antara tahun 2000 hingga 2002, 37\% pencari suaka berkaitan dengan terorisme yang dianggap sebagai ancaman layaknya konsep dalam teori fundamentalis yang terkait dengan Islam. Menurut riset psikologi selama 10 tahun, ditemukan bahwa terdapat hubungan kuat antara pencari suaka, pengungsi, terorisme dan prasangka terhadap muslim (Packham, 2007). Murray Edelman (1988) menyatakan bahwa wacana Australia untuk mengikuti Australia mengikuti peristiwa 9/11 memungkinkan kontrol politik yang memunculkan ketakutan dan kecemasan, sehingga perhatian publik akan teralihkan sehingga dukungan politik mereka bertambah.

Fakta diatas menunjukkan bahwa Islamophobia di Australia sebagain berasal dari pencari suaka dan imigran. Selain itu berbagai peristiwa menjadi titik balik bagi umat Muslim seperti peristiwa 9/11, bom Bali 2002, Madrid 2004, bahkan London 2005 di mana seluruh komunitas muslim tertuduh (Lean, 2012). Bangkitnya Pauline Hanson yang terkenal kejam mengkritik masyarakat adat multikulturallis dan minoritas kelompok. Bahkan, ia pernah menyatakan Muslim boleh tinggal di Australia jika ia beradaga Kristen (Packham, 2007). Di Camden, pada 2007, kepala Babi dihiasi bendera Australia berada di situs yang akan dijadikan sekolah Islam (Kruger, 2007; Al-Natour, 2010). Tahun 2011 terjadi kampanye untuk menghalangi kelompok Muslim menggunakan rumah ibadah di Pinggiran kota East St Kilda Melbourne (AJDS, 2011). Pada pertengahan 2014, terjadi penolakan pembangunan Masjid di Victoria, Bendigo. Penduduk sekitar menyatakan bahwa Masjid akan membawa kekerasan ke Bendigo dan membuat hukum Syariah diterapkan. Bahkan salah satu penduduk menyatakan, "Jika anda seorang Muslim dan menginginkan Masjid, silahkan ke Timur Tengah, ini Australia” (ABC News, 2014).

\section{Media Sosial Sebagai Alat Counter Islamophobia}

Islamophobia merupakan stereotip yang dimiliki oleh orang-orang dengan pengetahuan tengtang Islam yang sangat minim. Pada era informasi dan teknologi saat ini pengetahuan maupun informasi dapat didapatkan tidak hanya dari buku maupun internet, namun bisa juga melalui media sosial. Media sosial dapat berperan dalam pencegahan maupun pengembangan suatu isu, termasuk Islamophobia terhadap khalayak.

Menurut Natasha Zeitel-Bank, hubungan antara media sosial dan masyarakat dipengaruhi oleh empat hal. Pertama, perilaku individu, yakni hubungan antara media sosial dengan kehidupan. Hal ini dipengaruhi oleh intensifitas penggunaan media sosial dalam kehidupan sehari-hari. Kedua, usia, yakni usia memiliki pengaruh terhadap perilaku ketika berkaitan dengan media sosial. Ketiga, kepribadian, yakni diberbagai beranda di media sosial terdapat berbagai kepribadian. Keempat, perbedaan individu ketika melakukan kontak sosial di dunia nyata maupun virtual (Zeitel-Bank, 2014). Zeitel- 
Bank juga menambahkan bahwa kekuatan media sosial mempengaruhi kemampuan individu cenderung mandiri. Empat hal diatas dapat berlaku apabila interaksi sosial dalam dunia virtual merupakan aktivitas pendukun dalam membentuk persepsi terhadap isu tertentu.

Kekuatan media sosial untuk menghentikan atau meminimalisir isu dimanfaatkan oleh salah satu organisasi di Australia, yakni Onepath Networks. Jaringan Onepath Networks didirikan oleh Mala Manjanni pada bulan Maret tahun 2014 di Sydey, Australia. Jaringan ini berisi mengenai video dan film dokumenter untuk berdakwah sehingga pandangan negatif mengenai Islam akan memudar. Media sosial yang dituju adalah Youtube, Facebook, Instragram, bahkan bioskop. Mulai awal didirikan hingga bulan Februari 2018, jumlah video yang telah dirilis sekitar 500 video. Hal ini merupakan strategi yang begus karena penduduk Australia sangat aktif terhadap media sosial.

Konten yang diunggah berkisar mengenai cerita Islam dan dialog mengenai agama Islam. Hal ini berguna untuk menciptakan dialog dan pemikiran baru mengenai Islam, sehingga pemikiran penduduk mengenai Islam mulai terbuka. Stereotip Islam perlahan mulai diubah untuk mengurangi diskriminasi dan pandangan buruk tentang Islam. Upaya ini mendapatkan respon yang positif dari berbagai pihak, hal ini dibuktikan dengan berbagai perkembangan umat Islam di Australia.

Ridwan Jadwat menyatakan bahwa Australia sudah berbeda dengan Australia masa lalu, karena Australia mulai mengikutsertakan Muslim dalam berbagai bidang, termasuk dalam bidang pemerintahan. Selain itu, Islam adalah salah satu agama yang paling cepat berkembang di Australia. Hal ini ditandai dengan banyak masjid yang dibangun, sekolah Islam, dan daging restoran halal. Pada bidang lain, Muslim Australia sudah banyak ikut dalam anggota parlemen, dokter, pengacara, diplomat, militer, polisi, bahkan pengusaha. Pemerintah Australia juga semakin terbuka dengan Imigran. Australia mulai mempromosikan multikultural dan mengakui semua tradisi dan kepercayaan penduduknya. Terdapat lebih dari 130 tradisi keagamaan ada di Australia, termasuk lebih dari 600.000 umat Muslim.

\section{KESIMPULAN}

Islam di Australia bisa dikatakan sebagai agama yang minoritas. Meskipun begitu, Islam di negara ini masih tetap berkembang. Perkembangan Islam di Australia dibayangi oleh isu Islamophobia yang terus berkembang. Islamophobia di Australia dikaitkan dengan pencari suaka, imigran, teorisme dan Muslim. Perkembangan Isu Islamophobia mencoba diminimalisir oleh salah satu organisasi Onepath Networks dengan dakwah dengan memanfaatkan media sosial. Hal ini mendapatkan perhatian sehingga membawa perubahan bagi Australia, dibuktikan dengan keikutsertaan umat Muslim di berbagai bidang, pembangunan Masjid, sekolah Muslim dan fasilitas halal.

\section{UCAPAN TERIMAKASIH}

Terimakasih kami sampaikan pada pengelolah jurnal Kanal yang telah bersedia menerima dan mempublikasikan naskah kami.

\section{REFERENSI}

ABC News. (2014). Bendigo Mosque: Council Approves Mosque Despite Fierce Protests. ABC News. Retrieved June, 02, 2020, from http://www.abc.net.au/news/2014-06-19/bendigo-council-approvesmosque-despite-objections/5534634

Al-Natour, R (2010). Folk devils and the proposed Islamic school in Camden. Continuum 24(4), 573-585

Australian Human Rights Commission (AHRC). (2011). Freedom of Religion and Belief in 21st Century Australia. Sydney: AHRC.

Australian Jewish Democratic Society (AJDS). (2011). AJDS condemns hysteria over Muslim prayers at neighbourhood house. The Blog. Retrieved June, 02, 2020 from http://www.ajds.org.au/348/

Berg, C. (2014). The Redundancy Of New Anti-Terrorism Laws. ABC News. Retrieved June, 02, 2020, from http://www.abc.net.au/news/2014-0930/berg-the-redundancy-of-new-terrorism-laws/5778076.

Bouma, Gary D. (2011). Islamophobia As A Constraint To World Peace: The Case Of Australia. Islam and Christian-Muslim Relations 22(4), 433-441.

Burke, Kelly. (2012). Disunity, Not Anger, Is Muslim Dilemma. The Sydney Morning Herald. Retrieved June 02, 2020, from https://www.smh.com.au/nsw/disunity-not-anger-is-muslim-dilemma20120921-26c4m.html

Cesari, Jocelyne. (2011). Islamophobia in the West: a comparison between Europe and the United States' in John L. Esposito and Ibrahim Kalin (eds.) Islamophobia: the challenge of pluralism in the 21 st century. New York: Oxford University Press.

Dunn, K. (2001). Representations Of Islam In The Politics Of Mosque Development In Sydney. Tijdscrift voor Economische en Sociaale Geografie. 92(3), 291-308.

Edelman, M. (1988). Constructing the Political Spectacle. Chicago, IL: University of Chicago Press.

Esposito, J. (2011). Introduction. In: Esposito J and Kalin I (eds) Islamophobia: The Challenge of Pluralism in the 21st Century. Oxford: Oxford University Press.

Fidler, R (2011) John Howard on 9/11. ABC News. Retrieved June, 02, 2020, from http://www.abc.net.au/local/stories/2011/09/09/3313801.htm.

Hassan, Riaz., Lester, Laurence., Collinsm, Emily., Pretince, Patricia. (2018). Australian Muslim: The Challenge of Islamophobia and Social Distance 2018. International Center for Muslim and Non-Muslim Understanding, University of South Australia.

Houston, C., Butt, C., Mills, T., Spooner, R., Zielinski, C., Cook, H. (2014). Terror suspect shot dead after two police officers stabbed in Endeavour Hills. The Age. Retrieved June, 02, 2020, from http://www.theage.com.au/victoria/terror-suspect-shot-dead-after-twopolice-officers-stabbed-in-endeavour-hills-20140924-1015d4.html

Human Rights and Equal Opportunity Commission. (2004). Isma - Listen: National Consultations On Eliminating Prejudice Against Arab And Muslim Australians. Sydney, NSW, Australia: HREOC.

Isakhan, B. (2010). Orientalism And The Australian News Media: Origins And Questions, in Rane $\mathrm{H}$, Ewart $\mathrm{J}$ and Abdalla M (Eds) Islam And The Australian News Media. Melbourne. VIC. Australia: Melbourne University Press. 
Jatmika, Sidik. (2015). The Arab Spring 2010: Puncak Gunung Es Krisis Politik di Kawasan Timur Tengah. Jurnal Hubungan Internasional. 2(2), 157166

Kabir, N. (2006). Muslims in a 'White Australia': Colour or religion? Immigrants \& Minorities. 24(2), 193-223

Karaoglu, Seyda Nur (2018). A definition of Islamophobia in Étienne Dinet's The Pilgrimage to the Sacred House of Allah'. Thesis submitted to The Faculty of The Columbian College of Arts and Sciences of The George Washington University. Retrieved June, 02, 2020, from https://scholarspace-

etds.library.gwu.edu/downloads/g445cd431?locale=en (last accessed 11 June, 2018).

Kartini, Indriana. (2016). Minoritas Muslim di Australia dan Inggris. Jurnal Penelitian Politik, 3(1), 91-99.

Kruger, P. (2007). Pig Head Protest Over Planned Islamic School. The World Today. Retrieved June, 02, 2020, from http://www.abc.net.au/worldtoday/content/2007/s2105111.htm

Lean, N. (2012). The Islamophobia Industry: How the Right Manufactures Fear of Muslims. London: Pluto Press.

Library of Congress. Country Profile: Australia. Federal Research Division. Retrieved June, 02, 2020, from htpps://loc.gov/rr/frd/cs/profiles/Austalia.pdf\&ved=2ahUKEwj78Om B2DpAhUxIbcAHaA6ASAQFJAEegQIBhAB\&usg=AovVaw0A_4D OC7tUlxC7x3_AUIoe.

Manning, P. (2004). Dog Whistle Politics and Journalism: Reporting Arabic and Muslim People in Sydney Newspapers. Sydney: Australian Centre for Independent Journalism.

Melewar, T.C., Alwi, S. F. Syed. (2017). Islamic Marketing and Branding: Theory and Practice. Routledge, Taylor and Francis Group.

Melton, J. Gordon., Baumann, Martin. (2010). Religions of the World: A Comprehensive Encyclopedia of Beliefs and Practices. Retrieved June, 02, 2020, from https://books.google.com/books?id=v2yiyLLOj88C \&printsec=frontco ver\#v=onepage $\& \mathrm{q} \& \mathrm{f}=$ false

Mills, T. (2014). Police carry out terror raids in Flemington, Seabrook, Meadow Heights, Broadmeadows and Kealba. The Age, 30 September. Retrieved June, 02, 2020, from http://www.theage.com.au/victoria/police-carry-out-terror-raids-inflemington-seabrook-meadow-heights-broadmeadows-and-kealba20140930-10ntsz.html.

Om, Jason. (2015). Sydney's Muslim Community Sets Up TV Studio. ABC News. Retrieved, June, 03, 2020, from https://www.google.com/amp/s/amp.abc.net.au/article/6323814?espv= 1 .

Packham, B. (2007). Christian Muslims' welcome, says Hanson. News.com. Retrieved June, 02, 2020, from http://www.news.com.au/national/christian-muslims-welcome-sayshanson/story-e6frfkp9-1111113251407.

Packham, B. (2007). Christian Muslims' Welcome, Says Hanson. News.com. Retrieved June, 02, 2020, from http://www.news.com.au/national/christian-muslims-welcome-sayshanson/story-e6frfkp9-1111113251407.

Royal Institute of International Affairs. (2014). International Affairs. Retrieved June, 02, 2020, from www.jstor.org/publisher/riia.

Said, E. (1997). Covering Islam: How the Media and the Experts Determine How We See the Rest of the World, 2nd edn. London: Vintage.
Yusuf, Irfan. (2015). Editorial: One Path Network Undermines Extremist Rhetoric. The Sydney Morning Herald. Retrieved June, 03, 2020, from www.smh.com.au.

Zebiri, Kate. (2011). Orientalist themes in British Islamophobia,inJohn L. Esposito, and Ibrahim Kalin (eds.) Islamophobia: the challenge of pluralism in the 21st century. Oxford: Oxford University Press.

Conflict of Interest Statement: The authors declare that the research was conducted in the absence of any commercial or financial relationships that could be construed as a potential conflict of interest.

Copyright (C) 2021 Nurhalizah and Syakirin. This is an open-access article distributed under the terms of the Creative Commons Attribution License (CC BY). The use, distribution or reproduction in other forums is permitted, provided the original author(s) and the copyright owner(s) are credited and that the original publication in this jour-nal is cited, in accordance with accepted academic practice. No use, distribution or reproduction is permitted which does not comply with these terms. 